\title{
THE MICROSCOPIC FINDINGS IN FOUR GASSERIAN GANGLIA REMOVED FOR TRIGEMINAL NEURALGIA. ${ }^{1}$ WITH A RÉSUMÉ OF TWO PREviously EXAMINED.
}

\section{Sidney I. Schwab, M.D.,}

ST. LOUIS.

In the Annals of Surgery for June, Ig0 I, I reported the microscopic findings of the examination of two Gasserian ganglia removed by $\mathrm{Dr}$. Bartlett for persistent and very severe trigeminal neuralgia. The conclusions reached then in respect to the pathology of this disease were tentative, and it was for the purpose of testing their correctness that a study of four additional Gasserian ganglia was made. I am indebted for them to Drs. Bartlett, Mudd, and Carson, the latter for two, and I wish here to express my thanks for the specimens as well as for the clinical notes of the cases from which they were removed.

The experience in regard to methods of sectioning, staining and general technic gained in the previous study were of great use in the present series, and it can be justly said that changes which might be due to accidental causes have been avoided as much as it is possible to do so with the technical methods at present at our disposal. The value of the findings in the present series is further increased by the fact that two of the ganglia were removed before any peripheral operation had been done on the branches arising from them. In this way the traumatic effects of stretching, resection, and forcible evulsion were not present to invalidate whatever positive findings in the nerve cells were obtained. In one of them, the one numbered 5 , I have been able to use a technic for hardening, the most perfect that has as yet been devised. This method was employed and modified by Orr and Rows in studying the posterior root ganglia in dementia paralytica.

In the consideration of that ganglion, I shall refer to the technic more in detail. In the first ganglion studied the Marchi stain was very successful, and it showed beyond question that the effect of operation on the peripheral branches of a Gasserian

\footnotetext{
${ }^{1}$ Read before the St. Louis Medical Science Club, November II, I902.
} 
ganglion is to be seen in the production of marked changes in the peripheral branches.

For the general considerations of the anatomy and of the literature of this subject I shall refer to the article previously alluded to. Since that was published, I an unable to find any additional data of any importance on the microscopical study of such ganglia, although they must have been removed a great many times. I shall describe in some detail the findings in each of these ganglia, numbering them $3,5,6$, and 7 ; then I shall attempt to summarize them, with the view of bringing them into relation with the general pathology of trigeminal neuralgia. (The ganglion numbered 4 was omitted from this series on account of its imperfect condition.) I shall then lay before you, chiefly for your criticism, certain conclusions in regard to the pathology of trigeminal neuralgia, which the study of these six ganglia has seemed to justify.

In the paper previously referred to, certain conditions were laid down which should be always present before the findings in any given ganglion can be accepted without criticism. As I have had no reason to alter them, I shall state them again here. (I) A Gasserian ganglion, upon the peripheral branches of which surgical operations have previously been made, in the way of nerve stretching, resection, etc., is unfit for pathological study, or rather, any conclusions drawn from the findings must be for the most part invalidated for the reason that the mechanical effects of the operation may cause an ascending neuritis, which might produce changes in the ganglion itself, in the cells, or in the periganglionic tissue. (2) A Gasserian ganglion, which is removed by morcellation, or is much torn or cut, cannot be regarded as a favorable object for microscopical study. (3) No conclusion in regard to the condition of the nerve cells is justified unless they have been studied by the Nissl method or its various modifications. Of course the ganglion must be examined in a good state of preservation.

In regard to the general technic, I may add that three of the ganglia were imbedded in paraffin and one in celloidin. All of them were cut transversely and parallel to their largest diameter, so that every section contains the whole body of the ganglion, and the cells stained in such a section were the total number present at that level. Complete serials were made in every case, and sec- 
tions from different levels were stained, and only the most perfect were saved for study and description.

Ganglion No. 3. This ganglion was removed by Dr. H. G. Mudd from a patient about fifty years old, in I90I. In 1896 the infraorbital nerve was cut and pulled out at the infraorbital foramen, after being divided inside the orbit. The inframaxillary branch was cut at the mental foramen and the nerve evulsed. Cells: The cells toward the center of the ganglion are mostly normal, filling the cell spaces with almost no retraction. They take the stain however very irregularly, those staining most cleeply with the methylene blue or thionin, etc., show the greatest irregularity in form. The cells, in respect to their reaction to the stain, may be divided into two divisions: first, cells which are very nearly circular in outline, filling up the cellular spaces almost completely and staining very faintly, but otherwise normal in outline, nuclear position, and arrangement of Nissl bodies; second, cells which are very irregular in outline, smaller in size than the foregoing, showing marked retraction, and staining very intensely with the methylene blue stains and others of a like nature. These cells are fewer in number than the others, and most of the abnormal cells are found among them. In general they occupy a peripheral position in the ganglion body. They correspond in every way to similar groups of cells found in the first two ganglia studied, and seem analogous to a group of cells found by Head and Campbell in their study of the posterior spinal ganglia in herpes zoster. These writers supposed that such cells had to do chiefly with the function of pain, and therefore would show the most marked changes in a condition in which pain is the most prominent symptom. In a disease, such as neuralgia, where pain is the chiefest and most often the only symptom, changes in such cells might be expected to be present. These cells show almost every change which has come to be regarded as an evidence of the abnormal condition of a nerve cell. In most of them the changes seem to point rather to a disturbance of function than to a primary intracellular pathological process. I mean by that, that they show changes of outline and in the chromatic granules rather than in the position and character of the nucleus. In some few cells even the most profound alterations are present, such as migration or disappearance of the nucleus, total chromatolysis and cell disintegration. The pigment deposit in some of the cells is somewhat similar to that previously described in the ganglion numbered 2 in the former paper. This peculiar pigmentation is so unusual that it merits attention. Pigmentation in nerve cells is not commonly considered to be abnormal, that is, when it occupies the cell periphery, as is usually the case. The pigmentation found here is perinuclear. The nucleus 
is surrounded by a ring of pigment granules, varying considerably in size. The ring of pigment seems to lie above the nucleus, but the nucleolus is left free. In this specimen every tenth cell perhaps has such a perinuclear ring of pigment. It is to be noted that this curious pigment deposit is found mostly in the group of cells belonging to the first class, that is, the cells occupying the central part of the ganglion, which stain, as a rule, faintly and show otherwise little abnormality in outline or cell structure. Some cells show the usual peripheral deposit of pigment, to which no especial importance can be attached. Some of the sections, stained by Marchi for the study of degeneration in the peripheral branches, included cells from the body of the ganglion, because the cross sections of the roots were made close to the body of the ganglion. Some of the cells so included showed this perinuclear deposit, which stained black with osmic acid. Whether this is a proof of their fatty nature or not I am unable to say, but their appearance in such preparations is sufficiently striking to deserve mention.

Peripheral branches: In the study of the peripheral branches the Marchi and Van Gieson stains were used with good effect, especially the former. Portions of the three peripheral branches and also the sensory branch were cut both in cross section and longitudinally. In the first and second branches only very slight evidence of degeneration in the Marchi sense was observed. In the third branch marked degeneration was demonstrated. This consists chiefly in the usual clumps of degenerated myelin with swelling and knobbing of the axis cylinder. If you will remember that the third branch in this case had been forcibly evulsed some years ago, and that in all probability a slowly ascending neuritis resulted, these findings will be clear. Some of the sections from the sensory root show abnormal appearances by the Marchi stain.

It is rather difficult to explain this fact, because the changes are not characteristic enough to be designated as a neuritis. I am not inclined to believe that a neuritis of the sensory root exists of sufficient intensity to show itself by any microscopical method. If this were true, the good results obtained by the removal of the Gasserian ganglion would be hard to explain. It seems to me that what we have here is not a neuritis at all, but simply a destruction of the nerve fiber caused by the pressure of the forceps, for it must be remembered that in the modern operation, the sensory root is held tightly grasped by a locking forceps, while the ganglion body is being freed from its bed and while the peripheral branches are being cut. In the reports of the microscopical study of this subject, I have found one or two instances of neuritis of the sensory root, but they have not been studied carefully enough to make this point certain. It appears that the explanation above attempted is the fairer one at present. There was no definite alteration found 
in the blood vessels or in the connective tissue either surrounding the ganglion or lying between its cells.

Here and there throughout the ganglion free blood was found. The usual number of concentric bodies, the corpora amylacea, were present. The blood was no doubt produced by the operation. Summary: Cell changes, secondary in character, neuritis in the third branch, perinuclear pigmentation.

Ganglion No. 5. This specimen was removed by Dr. Bartlett from a woman about fifty-five years old. I think there had been no previous peripheral operation. This was a most perfect specimen. The case was of great interest clinically also for the reason that the patient developed, one or two days after the operation, a crossed paralysis, characteristic of a pontine lesion. This was caused, no doubt, by a slight hemorrhage into the pons, due to the tearing out of the sensory root. The paralysis cleared up within a week. I wish to say a few words concerning the method of hardening employed in this ganglion. It is a modification of Mann's method, and has for its object the avoidance of artifacts and the prevention of cell retraction. The authors claim for this technic that it presents an absolutely natural picture of the cells and that any retraction of the cells which is found must have existed before the specimen was hardened. This method was employed chiefly in the study of the posterior root ganglion, and for this reason is especially well adapted to the Gasserian ganglion. The similarity in anatomical structure between them has been previously pointed out in a former article. The method is as follows:

Fixing Solution: Picric acid, sat. sol.; sublimate, sat. sol.; formaldehyde. Equal parts. Three days.

Alcohol, beginning with forty per cent.

Thin celloidin.

Origanum oil, paraffin, equal parts, 12 hours, temperature, 45 to $50 \mathrm{deg}$.

Paraffin 12 hours.

The stain chiefly used was the Held toluidin blue, with a counterstain of erythrosin. This method gave satisfactory specimens.

Cells. The same irregularity that was noted in the previous specimen and the same division of cells were present. The cells lying in the periphery showed the same alterations in point of staining qualities and the same deviations from the normal. The centrally situated cells can, for the most part, be considered to be normal, with possibly a too faint staining reaction to be regarded as absolutely so. The smaller cells showed great irregularity in outline and in internal structure; some of them were so altered that they did not appear to be sensory cells at all. It is interesting to note the sharp contrast between the peripheral cells and those cells lying in the central part of the ganglion. The latter show no cell retraction at all, carrying out the contention of the authors al- 
luded to before, while the peripheral cells are often so shrunken that the spaces between the cells and their pericellular limits were often larger than the cell-bodies themselves. There was an almost complete absence of the perinuclear variety of pigmentation. Whatever abnormality there was seemed to be limited to the smaller peripheral cells, which, on the whole, showed very much the same deviation from the normal as the cells in ganglion numbered three. No alteration was found in the blood vessels or in the interstitial tissue. Peripheral branches, as well as they could be studied by the Van Gieson stain, show no evidence of degeneration. The specimen contained a large number of concentric bodies, scattered irregularly throughout.

Summary: Beyond the abnormal appearance of a group of small cells lying in the periphery of the specimen, very little abnormality can be found. This was the most perfect ganglion that I have examined, so that it can be taken as the one which best represents the appearance of the Gasserian ganglion removed for severe trigeminal neuralgia.

Ganglion No. 6. This ganglion was removed by Dr. Carson from a patient about fifty-four years old, who had previously not been operated upon. The specimen was imbedded in paraffin and was not a very satisfactory preparation, chiefly on account of the difficulty in obtaining sections that were thin enough. The Held stain was chiefly used.

Cells: They show more deviation from the normal than in any of the preceding specimens. The cells show the most marked alterations in outline. Here, as in the two preceding ganglia, the division into two sorts of cells seems to be justified. The cell changes consist for the most part in greatly irregular outlines with marked retraction of the cell-body. In many cells the nucleus occupies a peripheral position, and sometimes is entirely absent. Such cells as these can be said to be definitely pathological. Very few cells seem to be normal, even the centrally lying cells, found so nearly perfect in the two preceding specimens, are here changed. There is much pigmentation of the cells; the perinuclear variety being very frequent, though scarcely as marked as in ganglion No. 3 . The blood vessels and interstitial tissue appear normal.

Summary: Very definite and profound cell changes throughout the whole ganglion, irrespective of the position of the cells. The changes are so marked that they must be regarded as the seat of pathological changes in spite of the imperfection of the specimen from the microscopical point of view.

Ganglion No. 7. Removed by Dr. Carson from a patient upon whom no peripheral operation had been performed. The patient had been under treatment for a severe neuralgia for a period of ten years; during this time he had taken an immense amount of bromides and analgesics. The specimen was hardened in celloidin 
and stained by Niss1, thionin, and Van Gieson, etc. The specimen was much like ganglion No. 5 in general appearance and in stain reaction. Division of cells is the same as in the previous specimen. The changes consist in great irregularity of outline. The form of many of the cells is completely changed, from that of a round or oval body to an elongated or pyramidal one. The typical globular form of a sensory cell in the Gasserian ganglion is completely altered. The Nissl bodies are very irregular in their arrangement, the concentric form being seldom seen. Chromatolysis and vacuolization are seen to some extent, at least, in almost every cell. The cells themselves stain very irregularly; this causes a peculiar cell appearance, one part of the cell being deeply stained while another is almost without any stain at all, with absolutely no Nissl bodies to be made out. This peculiar intracellular stain reaction is not found in the cells of any other ganglion examined. In some of the cells lying deep in the ganglion there was a nuclear migration without any other cell change. This could be seen especially in the lightly stained cells. The number of abnormal cells in this ganglion is so large that they cannot be due to accidental causes. In the specimens are to be found very few normal cells, and the appearance of the ganglion as a whole is so different from the normal that one cannot escape from the conclusion that it is definitely the seat of pathological changes. There is no pigment deposit of importance and no alteration in the blood vessels or interstitial tissue.

The finclings in these four ganglia and in the two previously reported might be summarized as follows: In all of them a certain number of distinctly abnormal cells have been found. This number is too large to be accounted for by the accidental effect of faulty technic, or through hardening or straining processes. The cell changes have been found mostly in the peripheral portions of the ganglia, and in those cells which are characterized by staining deeply, by elongated outline, and by their small volume as compared to the cells which lie in the deeper portion of the ganglia. The changes found in the cells vary all the way from a slight degree of chromatolysis to profound changes of total cell disintegration and nuclear migration. In three of the six ganglia perinuclear pigmentation was present in large numbers of cells. This is so different in position and character from the pigment found in many normal cells, that it must be, for the present at least, regarded as a deviation from the normal. In one of the ganglia a sclerosis of the periganglionic tissue with excessive connective tissue formation around and between the cells was found, which was so pro- 
nounced that its pathological significance is unquestioned. In some of the ganglia neuritic changes were found in the peripheral branches, but only in those cases in which a peripheral operation had previously been done. No certain changes in the blood vessels could be demonstrated. Concentric bodies or corpora amylacea were found in all the specinens, but they have no interest beyond their chemical or histological study.

In view of these findings, then, there is this question which confronts us: Have we a sufficient basis for the establishment of a pathology of trigeminal neuralgia, that is, for a pathology based upon anatomical variations from the normal? Before discussing this question, it is well perhaps to consider something about the data upon which we have to rely for an answer. If these six ganglia do not afford any basis for the answer to this question, six more or sixty more will certainly not. All of these ganglia were from cases of the most severe form of neuralgia; in three of them there had been no peripheral operation to complicate the microscopical findings, and all of them were removed cleanly and given to me in a fresh state, well adapted for histological study. In other words, accidental sources of error were removed as far as it is possible to do so at present, and the most approved technic was used in preparing them, and as far as I know nothing was omitted in the way of staining, hardening and fixing to give accurate preparations. It seems then a fair conclusion that, if trigeminal neuralgia depends upon disease of the Gasserian ganglion, these six ganglia should show sufficient anatomic changes to explain its chief symptom. If, on the other hand, trigeminal neuralgia does not arise from disturbance of the Gasserian ganglion, then the changes here described must have some other explanation. A further conclusion is forced upon us, and that is that if the Gasserian ganglion is the seat of trigeminal neuralgia and no changes in the ganglion sufficiently intense to explain the symptoms can be demonstrated, then either our methods of microscopical examination are at fault, or it is impossible to connect changes in the nerve cell with manifestations of abnormal cell activity, as is shown in this disease by the frequent attacks of the typical neuralgic pain. There is little doubt in my mind now that the principal seat of all trigeminal neuralgic symptoms is found in a diseased condition of the Gasserian ganglion. The proof of this, and I can see no way 
out of it, is found in the complete disappearance of symptoms when the ganglion itself is removed, or when the sensory root is divided, as has lately been done by Frazier at Spiller's suggestion. As soon as the ganglion is isolated, that is, as soon as its sensory pathway to the brain, where, of course, the conscious manifestation of pain is situated, is blocked, at that instant neuralgia of the quintus ceases. In the face of this anatomical proof, we must conclude that the causes which produce the attacks of pain must have their anatomical origin in the cells, the tissue, or the nerve fibers which compose the structure of the ganglion. Having now localized the only possible seat of the disease, anatomically considered, we may take up the other two questions. As far as the reliance on microscopic technic is concerned, it can safely be stated that we can rely upon its results when the technic is followed out with reasonable care and when enough material of the same sort is present as to overcome the natural sources of error. Six ganglia and many hundreds of sections seem to me sufficient to overcome this difficulty.

It seems fair then to say that whatever changes in the ganglia were present were shown by the methods employed with sufficient accuracy to make use of them towards an explanation of the disease. Of course it must be recognized that the limits of microscopical technic are of themselves sufficiently narrow to prevent any but a crude attempt at the explanation of diseased function. The last question to be considered is the ever present diffculty of connecting abnormal cell conditions anatomically with abnormal cell functions physiologically. This in truth is the crux of the whole question, and it is by no means limited to the problem here under discussion.

Given a nerve cell or cells in a Gasserian ganglion from a case of trigeminal neuralgia, having presumably to do with the function of pain, how can we in our own minds connect, let us say, the migration of their nuclei with the agonizing pain present in all such cases? This very point has been recently discussed by Schenck in his monograph on the physiological basis of the neurone theory. He especially emphasizes the fact that physiological processes may go on in the nervous system without their cells taking an active part in them. If this is true physiologically it must be true in the pathological sense also. In considering the chief symptom of neuralgia, 
that is, the recurrent attacks of pain, we must face the fact that our conception of the possible causes of pain are narrowed down to two, and perhaps to a single element. Briefly, we can comprehend mechanical causes for pain in the larger sense of the term, such as pressure, stretching, weight, etc., and we can somewhiat as readily comprehend certain chemical causes of pain, such as for example, the effect of an acid on an exposed nerve fiber. We are able to do this because we have experienced their effects. All other causes we cannot correctly reason about because we cannot directly experiment with them on ourselves. For example, if we try to think of any intracellular cause for pain, we must deal immediately with purely metaphysical conceptions. That there exists, or rather that there can exist, a purely parenchymatous cause of pain, is altogether possible, but at present, pathology, as we know it, does not seriously concern itself with it. There is little doubt that certain cases of trigeminal neuralgia are caused by the effects of mechanical pressure on the ganglion. There have been a few cases reported where tumors or traumatic bone lesions were found sufficiently near the ganglion body itself to exercise mechanical pressure upon it. Sclerosis of the ganglion itself may also be regarded as a cause acting mechanically. The deposit of connective tissue by pressure on the nerve fibers may well produce the attacks of pain which we so well know. But these extrinsic causes, acting mechanically, must be but a small factor in the causation of neuralgia, for their presence is a matter of great rarity in the published reports on the study of Gasserian ganglia removed for neuralgia. It is well, however, to remember that this is an occasional factor.

There are two other explanations remaining. The toxic nature of the disease and the intracellular origin of it. These might well be taken together because I think they can in a measure be brought into relation with the abnormal findings present in these six ganglia. I take them together for another reason also, because they both remain an unknown quantity, and it is only through their assumed effects that we speak of then. First of all I want to emphasize the fact that the cell changes which I have described are not the causes of neuralgia in the sense of a primary cell disease, but are either the effects of an abnormal or a greatly exaggerated cell activity. Whether these cells are primarily concerned in the 
production of pain is of course an undecided question, but it seems very probable that they are. These abnormal appearances in the six ganglia examined mean that the cells so affected have been over active for a long period of time, or that they have been abnormally active, so that gradually they have lost their anatomical integrity. They may be in a measure compared to the nerve cells in a state of intense fatigue, which Hodge has pictured in his experiments made at Clark University some time ago. In so far then we have the right to regard these ganglia as pathological, and every ganglion removed for the severe grade of neuralgia, for which alone the operation is justifiable. ought to show, if carefully examined, such large numbers of cells abnormal in this sense, that some account of then must be made.

As to the active causes leading to such pathological activity, we are mostly in the dark and any attempt at explanation must be purely speculative. There are two reasonable explanations: first, that there is some toxin circulating in the blood, which has a selective action on the cells of the Gasserian ganglion, usually on one side, and especially on a certain group of cells which may have to do with the function of pain. The nature of this toxin is absolutely unknown. Second, the cells thenselves originate the toxin owing to some abnormal cell activity. That cells have this ability is proven by the recent studies on immunity. Possibly both of these factors are at work along with others of which we know as little. The results, after all, of this ganglion work in neuralgia, which at first sight are not very encouraging, are really of some importance, and I think that the line of inquiry which the study opens for us is well worth pursuing.

The following conclusions seem to be justified:

I. In six ganglia removed for trigeminal neuralgia, anatomic changes were found of sufficient importance to bring them in relation with the symptoms of this disease.

2. These changes in the cells do not point to them as the primary cause of neuralgia, but they may be taken to represent the effects of abnormal cell activity, the origin of which we are not able to point out.

3. The Gasserian ganglion is the anatomical seat of the chief symptom of trigeminal netralgia, that is the attacks of neuralgic pain. 